\title{
Human Health Cost of Air Pollution in Kazakhstan
}

\author{
Ussen Kenessariyev", Alexander Golub ${ }^{2}$, Michael Brody ${ }^{2}$, Askhat Dosmukhametov ${ }^{1}$, Meiram Amrin ${ }^{1}$, \\ Aya Erzhanova1, Dinara Kenessary ${ }^{1}$
}

${ }^{1}$ Department of Public Health, Kazakh National Medical University Named after S.D. Asfendiyarov, Almaty, Kazakhstan; ${ }^{2}$ Department of Environmental Science, American University, Washington DC, USA.

Email: mbrody@american.edu

Received December $11^{\text {th }}, 2012$; revised February $5^{\text {th }}, 2013$; accepted April $9^{\text {th }}, 2013$

Copyright (C) 2013 Ussen Kenessariyev et al. This is an open access article distributed under the Creative Commons Attribution License, which permits unrestricted use, distribution, and reproduction in any medium, provided the original work is properly cited.

\begin{abstract}
Kazakhstan, like other former Soviet Republics, inherited a number of serious environmental problems. Air pollution is one of these serious problems, leading to significant environmental health effects on the population of Kazakhstan. This study provides a baseline analysis of health damages from air pollution, based on readily available information. Mean estimates of mortality risk attributable to air pollution are about 16,000 cases per year with a $95 \%$ confidence level of the risk not exceeding 25,500. Even taking into account all the uncertainties related to the collection and processing of primary data, as well as the application of risk analysis methodology, we conclude that air pollution in Kazakhstan constitutes a significant contribution to the environmental burden of diseases. In relative terms, the impact of air pollution on premature mortality in Kazakhstan is notably higher than in Russia and the Ukraine.
\end{abstract}

Keywords: Air Pollution; PM; Kazakhstan; Health Risk; Uncertainty

\section{Introduction}

Kazakhstan, geographically the largest of the former Soviet republics, excluding Russia, possesses enormous fossil fuel reserves and plentiful supplies of other minerals and metals. It also has large energy and agricultural sectors which account for a significant fraction of GDP. On post-Soviet territory, Kazakhstan is the most rapidly growing economy. Kazakhstan's economy has largely recovered from the global financial crisis of 2008, and consequently, GDP increased 7\% per year until 2011. Extractive industries have been and will continue to be the engine of this growth. These industries have an adverse effect on the environment. The combination of large coal and energy sectors results in high levels of air pollution. Recently, Kazakhstan has embarked on an ambitious diversification program aimed at developing targeted sectors like transportation, pharmaceuticals, telecommunications, petrochemicals and food processing. In 2013, the government expects to join the World Trade Organization. This move should further help Kazakhstan develop its manufacturing and service sector base. Integration into the world economy will additionally boost economic growth and create new opportunities for diversification of economic growth. However, it also may create additional burdens on the environment.
Like other former soviet republics, Kazakhstan inherited significant environmental problems, but relatively little analysis of their effects. However, a number of studies in the region conducted in 1996-2008 have estimated health risks from air pollution in Russia and Ukraine [1-6]. These studies generally conclude that there are significant health risks attributable to environmental pollution. According to these studies, up to $90 \%$ of adverse health effects could be attributed to air pollutants [5], and primarily to PM 2.5. The similarity of Kazakhstan's industrial profile and pollution levels with Russia and Ukraine, suggests that these conclusions will likely hold true for Kazakhstan. The observed similarities between the countries prompted the undertaking of the current study. This is the first time that a human health risk analysis was conducted in Kazakhstan. This study also provides a baseline analysis of health and economic costs of environmental pollution in Kazakhstan, using currently available information.

The goal of this study is to demonstrate the general magnitude of the adverse effects of environmental pollution on human health and to examine the level of uncertainty for the major conclusions. Finally, this study should draw attention to the problem of air pollution in Central Asia and provide some guidance for future research. 


\section{Description of Study Area}

Kazakhstan is the largest landlocked country in the world. It has a relatively dry climate with hot Central Asian summers and can have extremely cold winters. Parts of the year can be marked by sand storms, which are typical for the south and center of the country. The two largest cities are the former capitol, Almaty and the new capitol, Astana. Almaty is located in the southeast of the country, is in a broad valley, closed on three sides by the mountains. Astana is on the steppes in north central Kazakhstan has hot and dry summers, and a Siberian winter.

As of 2010, the overall population of Kazakhstan was $16,200,000$. The average age of the population is about 30 years, with an average life expectancy of 63.51 for men and 73.32 for women. Unemployment rate is just under $6 \%$. (official national statistics, http://www.eng.stat.kz/)

\section{Methods}

This study was conducted primarily utilizing reported data that is readily available in Kazakhstan and by applying the risk analysis methodology described in [7]. The analysis includes reported ambient concentrations and baseline mortality in cities across Kazakhstan.

This study is similar to the one conducted for Russia [5] and Ukraine [4]. These studies demonstrated how health risk analysis could be adapted and applied in the former Soviet Union, taking into account important factors such as data availability, demographics, and the composition of industrial emissions.

This study required the following steps and the methods section is organized by these steps:

1) Acquisition and analysis of official monitoring data of Total Suspended Particles (TSP).

2) Conversion of TSP concentration to PM10 concentration.

3) Conversion to PM 2.5 concentration from PM10.

4) Application of a PM2.5 log-linear concentrationresponse function.

5) Collection of the mortality and morbidity data, and finally.

6) Monte Carlo analysis to better account for uncertainties in the data and model.

\subsection{Particulate Data in Kazakhstan}

Systematic, country-wide monitoring of PM2.5 or PM10 is not available in Kazakhstan. As in most other postSoviet countries, particulate monitoring and reporting is still based only on total suspended particles. Ambient TSP concentration is usually monitored and reported only for larger cities, and not in smaller cities, towns or rural areas. However, big cities are "hot spots" in terms of concentration of TSP. Due to these information constraints, we focused on bigger cities with high reported levels of pollution. As a result, total risk attributed to air pollution is likely underestimated as the study does not cover the entire country. We address this and other shortcomings of the study in the section where we present the results of the uncertainty analysis.

Concentrations of TSP are reported in the official statistics of the Kazakh HydroMeteorological Agency (www.kazhydromet.kz). Monitoring stations are a combination of automatic and manual samplers. Automatic monitors take TSP samples every 6 hours. The number of monitors for each city in the study is shown in Table 1 below.

We calculated an average monthly TSP concentration over 3 years $(2008,2009$ and 2010) for each city in the study. As an example Table 2 shows the data for Astana, the capital of Kazakhstan.

The ambient concentration data in Table 2 exhibit significant variability within years as well as within monthly observations. One important aspect in understanding TSP in Kazakhstan, however, is the occurrence of sandstorms that complicate the conversion of TSP to PM. The absolute maximum TSP concentration of $1260 \mu \mathrm{g} / \mathrm{m}^{3}$ was observed in April 2008, and the minimum of $250 \mu \mathrm{g} / \mathrm{m}^{3}$ was observed twice during the winter, once in February 2008 and a second time in December 2009. Such a difference in concentrations is likely due to the effect of sandstorms. The highest TSP concentrations are usually reported from April to October. This is consistent with the hypothesis about the effects of sandstorms.

\subsection{Conversion of TSP to PM10}

Avaliani and Revich [8] proposed a 0.55 conversion coefficient to convert TSP into PM10 for Russia, slightly

Table 1. Location and number of TSP monitoring stations.

\begin{tabular}{cc}
\hline City & Number of Monitoring Stations \\
\hline Almaty & 16 \\
Astana & 7 \\
Shimkent & 4 \\
Zhezkazgan & 2 \\
Taraz & 5 \\
Pavlodar & 2 \\
Ust-Komenogorsk & 5 \\
Semey & 2 \\
Atyrau & 7 \\
Temirtau & 3 \\
Aktau & 2 \\
\hline
\end{tabular}

Source: National statistics, KazHydroMet, 2011. 
Table 2. Average monthly TSP concentration in Astana.

\begin{tabular}{ccccccccccccc}
\hline Year & Jan & Feb & Mar & Apr & May & June & July & Aug & Sep & Oct & Nov & Dec \\
\hline 2008 & 290 & 250 & 420 & 1260 & 900 & 900 & 480 & 600 & n.a. & 640 & 530 & 700 \\
2009 & 290 & 530 & 380 & 500 & 400 & 450 & 450 & 450 & 420 & 540 & 510 & 250 \\
2010 & 260 & 410 & 460 & 820 & 720 & 530 & 490 & 550 & 800 & 580 & 280 & 350 \\
\hline
\end{tabular}

Source: Informational Bulletin on Environmental Conditions, Ministry of the Environment, RSE KazHydroMet, 2011.

below the 0.6 conversion coefficient suggested in Larson et al. [1] for Russia and in Strukova et al. [4] for Ukraine. Many fo rmer Soviet regions have more combustionrelated activities than average, so using a higher coefficient to convert TSP to PM10 than the world average coefficient of 0.5 would be appropriate [5]. However, the slightly more conservative coefficient of 0.5 was used in this study.

\subsection{Conversion of PM10 to PM2.5}

In Russia, the PM 2.5/PM10 ratio have estimated ranges of $0.55-0.75$ [1] and in Cohen et al, [9]. The ratios of PM 2.5/PM10 vary for emission sources with different types of technologies, industrial sectors, fuels, and by distance from emission sources to monitoring locations, etc. Therefore, it appears that conversion coefficients calculated for Russia and Ukraine should be applicable in Kazakhstan. However, with the difference in climatic conditions, particularly sandstorms, it is not possible to use this conversion range in Kazakhstan.

As Shahsavani et al. [10] report, the PM 2.5/PM10 ratio during sandstorms is close to 0.2 . However, the ratio is at the 0.4 level when there are no sandstorms. For example, in the United States, the conversion ratio in arid/ semi-arid states (Arizona, Nevada, New Mexico, and Utah) generally falls in the range of $0.2-0.4$, and in the range of $0.4-0.5$ in agricultural states like Iowa, Kansas, and Missouri. The range is $0.55-0.75$ in more forested states with less agriculture (Pennsylvania, Virginia, West Virginia; http://www.epa.gov/air/data/reports.html).

Cities that are not located in arid/semi-arid or agricultural zones, but have high traffic emissions and relatively low fugitive road dust, will tend to have very high PM2.5/PM10 ratios. It is plausible that the PM ratio in Kazakhstan falls in the range of $0.2-0.5$. The exact ratio depends on fugitive road dust, the influence of industrial emissions on urban PM ambient concentrations, and on the size distribution of particulates from industrial sources.

In Kazakhstan, as in Russia and Ukraine, coal-fired power contributes a significant portion of air pollution. Based on these observations, a ratio of PM 2.5/PM 10 of 0.4 has been applied to areas of Kazakhstan that have significantly fewer sandstorms. This includes Almaty, the largest city in Kazakhstan and is located in a mountainous area. For areas more prone to sandstorms, such as in a steppe area like the capital, Astana, we used lower conversion coefficients of either 0.2 or 0.3 depending upon the known local severity of sandstorms. Finally, to help bound these estimates; we compared them to estimates from remote sensing analysis [11].

\subsection{Concentration-Response Coefficient}

The WHO in the World Health Report [12] provided a global estimate of the health effects of environmental risk factors. The estimation of air pollution-related mortality was based on a concentration-response coefficient, and a log-linear model that links ambient pollutant concentrations with cardiopulmonary mortality. This approach based on Pope et al. [13] makes the best use of available concentration data and the evidence of the mortality effects of ambient particulate pollution (PM 2.5). Dockery [14] in his review of the health effects of PM discusses this approach at length. Alternative approaches would require building a local time-series database as in Zmirou et al. [15] but without the corresponding high quality PM monitoring database.

This particular analysis was based on [7], who suggested using this log-linear approximation of health risk function as in expression (1) whereas other authors suggest linear approximations. For instance, one of the most recent studies conducted for the US [16] suggest a linear approximation. Additional relative risk would be calculated per $10 \mu \mathrm{g} / \mathrm{m}^{3}$ of PM with a diameter less than 2.5 microns in [7]. Linear approximation implies an equal weight of each incremental increase in concentration while log-linear function implies decreasing return with additional increase in concentration. Accordingly, approximation (1) mimics this property of concentrationresponse function as long as $\beta<1$ holds true. The selection of (1) instead of a simple linear approximation is important for risk analysis when ambient concentration is high, and leads to overall more conservative estimates of risk.

$$
R R=\left(\frac{C+1}{C_{0}+1}\right)^{\beta}
$$

where RR stands for relative risk;

$\beta$-is a concentration-response coefficient;

$C$ denotes concentration of PM2.5;

$C_{0}$ represents concentration threshold (usually $7.5 \mu \mathrm{g} / \mathrm{m}^{3}$ 
like a background concentration as in [13]);

In order to translate relative risk into population risk, we multiply the baseline mortality by the calculated relative risk and an exposed population (2):

$$
R=R R \times M^{0} \times \rho o p
$$

$M^{0}$ - a baseline mortality net of adverse health effect of pollution;

pop-represents the exposed population.

Unfortunately for this study on the current level of the negative health effects of pollution, there is no study of the "net baseline mortality". Reported mortality statistics do not separate out effects attributable to air pollution. In other words:

$$
M=M^{0}+M^{0} \times R R
$$

$\mathrm{M}$ denotes a reported mortality (cardio-pulmonary in case of PM2.5);

Then baseline mortality could be expressed as a function of the reported mortality:

$$
M^{0}=\frac{M}{1-R R},
$$

which leads to (3):

$$
R=\frac{R R-1}{R R} M \rho o p
$$

The concentration-response coefficient $(\beta)$ represents the change in health outcomes per unit of pollution. In the linearized model, this coefficient is the slope of the linear concentration-response function.

Pope et al. [13] provides a comprehensive and detailed study to date on the relationship between air pollution and mortality. The study confirms and strengthens the evidence of the long-term mortality effects of particulate pollution found earlier. Pope et al. [13] utilized ambient air quality data from metropolitan areas across the United States for the two periods 1979-1983 and 1999-2000, and information on certified causes of mortality of adults in the American Cancer Society (ACS) database over a period of 16 years. The ACS database contained specific information obtained through questionnaires surveying more than 1 million adult individuals. The study could therefore control for a large set of factors that may also affect variations in mortality rates such as age, smoking behavior, education, marital status, body weight, occupational risk factors, and dietary indices across metropolitan areas.

The study found a statistically significant relationship between levels of PM2.5 and mortality rates, controlling for all the factors discussed above. Pope et al. [13] estimated relative risk for the linear function for cardiopulmonary mortality:

$$
R R=\exp \left(\beta\left(X-X_{0}\right)\right)
$$

RR stands for relative risk for cardiopulmonary mortality, $X$ is the observed PM2.5 concentration and $X_{0}$ is a background PM 2.5 concentration, which is equal to $7.5 \mathrm{ug} / \mathrm{m}^{3}$ as in WHO [12].

In the underlying Pope et al. [13] study, the estimated increase in cardiopulmonary mortality was 6 - 9 percent, and 8 - 14 percent for lung cancer per $10 \mathrm{ug} / \mathrm{m}^{3}$ of PM2.5. The former two risk ratios could be applied in this study. However, as we can see from Table 3, the average annual PM2.5 concentration in Kazakhstan is well above the range of the original Pope et al. (2002) study ${ }^{1}$.

For higher PM2.5 concentrations than what Pope considered in his analysis, Ostro [7] proposed using loglinear relative risk function from cardiopulmonary mortality to reflect the uncertainty about the health impact with higher PM2.5 concentration. The log-linear relative risk function for cardiopulmonary mortality has the form described above: see expression (1). The concentration response coefficient $\beta$ for cardio-pulmonary mortality is equal to 0.15515 [7].

\subsection{Monte Carlo Analysis}

Monte-Carlo simulations were used to estimate the combined uncertainties of two types, the monitoring data and the model of additional mortality attributed to air pollution. Using TSP data from a monitoring network based on old standards and converting these data to PM2.5 has certain, but unknown uncertainty. Even with the possibility of unknown systematic errors in this conversion process, our estimates all fell within empirically derived bounds from the remotely sensed data [11]. Additionally there are always underlying parameter uncertainties in the risk model, despite the many years of use and general

Table 3. Population and cardiovascular mortality in selected cities of Kazakhstan.

\begin{tabular}{ccc}
\hline City & $\begin{array}{c}\text { Total population } \\
\text { (millions) }\end{array}$ & $\begin{array}{c}\text { Cardiovascular } \\
\text { mortality per } \\
\mathbf{1 0 0 , 0 0 0}\end{array}$ \\
\hline Almaty & 1.39 & 446 \\
Astana & 0.63 & 205 \\
Shimkent & 0.45 & 260 \\
Zhezkazgan & 0.35 & 426 \\
Taraz & 0.30 & 335 \\
Pavlodar & 0.25 & 577 \\
Ust-Komenogorsk & 0.31 & 609 \\
Semey & 0.30 & 491 \\
Atyrau & 0.17 & 213 \\
Temirtau & 0.14 & 704 \\
Aktau & 0.17 & 223 \\
\hline
\end{tabular}

Source: official national statistics.

${ }^{1}$ Under $20 \mathrm{ug} / \mathrm{m}^{3}$. 
verification of these models. Thus, even with these uncertainties in data and models we can offer an educated guess regarding distributions of the underlying parameters in the formulas for calculation of mortality risk. To carry out the Monte-Carlo simulation we used Crystal Ball 11.11.

We thus assumed that there is no correlation among independent variables [in this case estimated PM2.5 concentrations in different cities, and the risk mortality function]. Thus we were able to run Monte-Carlo simulations in order to calculate combined uncertainty of additional mortality we attribute to air pollution. The Beta PERT distribution (with parameters: $\min =5, \max =10$ and likelihood $=7.5$ ) was applied for the threshold case, and parameters $(\min =0.06, \max =0.25$ and likelihood $=$ 0.16 ) for the case to preclude generation of negative PM 2.5 values Additional reasons for the use of this probability distribution include important but unknown levels of various confounding factors specific to Kazakhstan such as smoking, drinking, and indoor air pollution levels as examples. Nonetheless, the Monte-Carlo simulations generated a wide range of different states and the distribution of outputs covers all plausible range of potential outcomes. Results of Monte-Carlo simulations are shown in Table 5.

\subsection{Mortality Data and Population}

Background mortality plays a critical role in population risk calculation. The total population of the highly polluted cities with reported pollution data listed in Table 3 is about 4.5 million. It is about $50 \%$ of the urban population in Kazakhstan and $30 \%$ of the total Kazakhstan population in 2010 [17]. The latest available data on mortality is presented in Table 3.

There is a significant difference in cardiovascular mortality per 100,000 of population across the cities. This difference could be partially explained by the different age structures of each city's population, climatic conditions, but also potentially by the difference in air quality.

\section{Results}

The concentrations of the 3 classifications of particulate matter for each of the cities in this study are shown in Table 4. The mortality effects attributable to PM2.5 concentrations are then shown in Table 5.

By far, the highest number of deaths attributable to air pollution is in Almaty. The high mortality could be explained by the fact that Almaty has a relatively high PM2.5 concentration and one of the highest crude mortality rates as well as having the largest population (more than double that of Astana, the next largest city). These results with their associated probabilities are shown in Figure 1 for the selected cities of the study and in Figure 2 for the rest of Kazakhstan.

\section{Discussion}

This study used official monitoring data, and went through a series of established calculations to address health risks from particulate matter. Although the input data, assumptions and results of the study exhibit significant uncertainty, one can conclude that even a conservative interpretation of the results of the study suggest that industrial air pollution constitutes a substantial problem in Kazakhstan. Our mortality estimates are several times higher than the reported 2200 cases of mortality attributed to outdoor air pollution by WHO in their series "Country Profile for Environmental Burden of Disease" (http://www.who.int/quantifying_ehimpacts/countryprofi leseuro.pdf). One important difference is the annual average ambient concentration used in the analysis. While WHO reports $25 \mu \mathrm{g} / \mathrm{m}^{3}$ ambient PM10 concentrations, we found that the actual numbers are far higher, depending upon the city (see Table 4). The data from Brauer et al. [10] also support the use of higher estimates than from the WHO analysis.

Although absolute numbers in Kazakhstan are lower than in Russia and the Ukraine, in relative terms, air pollution constitutes a more severe environmental prob- lem in Kazakhstan than in other post-Soviet countries. Kazakhstan's problem could be partly explained by the fact that it has the relatively highest share of coal in its energy mix. Coal combustion is one of the leading sources of PM 2.5 emission in post-Soviet countries [3,18]. Table 6 demonstrates the magnitude of health risk attributed to air pollution in Kazakhstan relative to Russia and the Ukraine.

From the mortality data in Table 6, one can conclude that the contribution of air pollution to total mortality in Kazakhstan is higher than in Russia and Ukraine.

Table 4. Annual average concentrations $\left(\mathrm{mg} / \mathrm{m}^{3}, 2008-2010\right)$ of monitored TSP (column 2) estimated PM-10 (column 3) and PM-2.5 (column 4). PM-2.5 concentration range based on remote sensing (column 5).

\begin{tabular}{ccccc}
\hline City & TSP & PM10 & PM2.5 & $\begin{array}{c}\text { PM2.5 } \\
\text { concentration }\end{array}$ \\
\hline Almaty & 284.6 & 142.3 & 56.9 & $40-60$ \\
Astana $^{*}$ & 529.2 & 264.6 & 52.9 & $40-60$ \\
Shimkent $^{* *}$ & 203.3 & 101.65 & 40.7 & $40-60$ \\
Zhezkazgan $^{* *}$ & 345.5 & 172.75 & 51.8 & $40-60$ \\
Taraz & 133.6 & 66.8 & 26.7 & $20-40$ \\
Pavlodar & 141.9 & 70.95 & 28.4 & $20-40$ \\
Ust-Kamenogorsk $^{2}$ & 160.8 & 80.4 & 32.2 & $20-40$ \\
Semey & 152.6 & 76.3 & 30.5 & $20-40$ \\
Atyrau* & 432.7 & 216.35 & 64.9 & $60-80$ \\
Temirtau & 217.3 & 108.65 & 43.5 & $40-60$ \\
Aktau & 237.5 & 118.75 & 47.5 & $40-60$ \\
\hline
\end{tabular}

${ }^{*}$ Conversion factor PM10 to PM2.5 - 0.2. ${ }^{* *}$ Conversion factor PM10 to PM2.5 -0.3 . 
Table 5. Additional mortality attributable to PM2.5 concentrations in selected cities of the study and the rest of Kazakhstan.

\begin{tabular}{|c|c|c|c|c|c|}
\hline $\begin{array}{l}\text { Selected Cities of Study \& } \\
\text { Rest of Kazakhstan }\end{array}$ & $\begin{array}{c}\text { Base Case } \\
\text { Calculated PM2.5 value }\end{array}$ & Mean & $\begin{array}{l}\text { Standard } \\
\text { Deviation }\end{array}$ & Minimum & Maximum \\
\hline Almaty & 1666 & 1638 & 197 & 985 & 2352 \\
\hline Astana & 322 & 324 & 39 & 200 & 467 \\
\hline Shimkent & 259 & 285 & 35 & 171 & 424 \\
\hline Zhezkazgan & 373 & 377 & 45 & 234 & 534 \\
\hline Taraz & 170 & 186 & 29 & 92 & 306 \\
\hline Pavlodar & 249 & 264 & 41 & 134 & 430 \\
\hline Ust-Komehogorsk & 354 & 355 & 54 & 169 & 558 \\
\hline Semey & 271 & 278 & 43 & 134 & 451 \\
\hline Atyrau & 99 & 103 & 12 & 65 & 141 \\
\hline Temirtau & 222 & 238 & 29 & 146 & 346 \\
\hline Aktau & 90 & 94 & 11 & 57 & 133 \\
\hline Sub-Total Selected Cities & 4075 & 4140 & 491 & 2590 & 5973 \\
\hline Rest of Kazakhstan & 12042 & 12372 & 2098 & 4638 & 19445 \\
\hline Total for Kazakhstan & 16117 & 16512 & 2452 & 7504 & 25419 \\
\hline
\end{tabular}

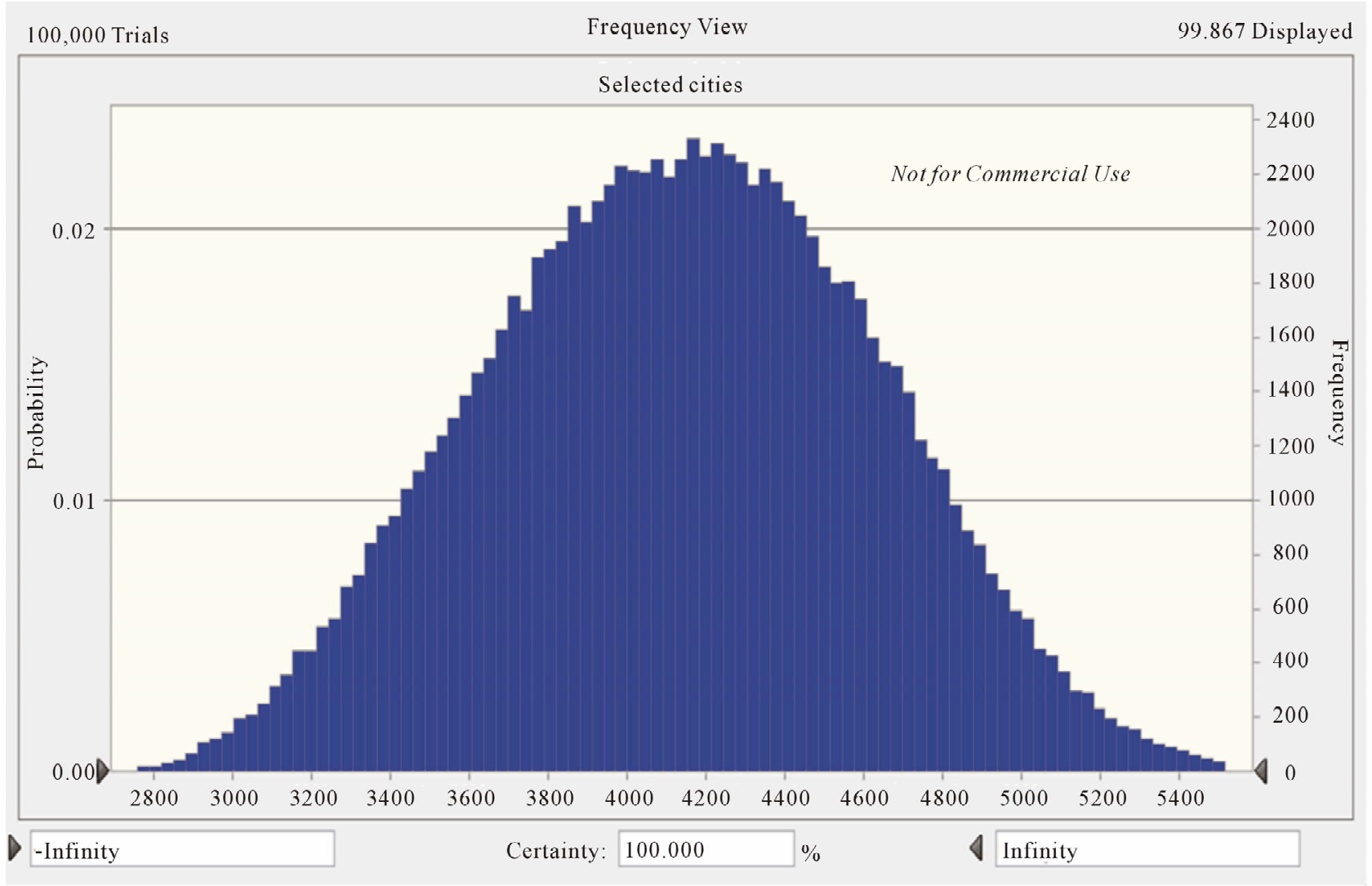

Figure 1. Mortality attributed to PM2.5 pollution in selected cities of study. 


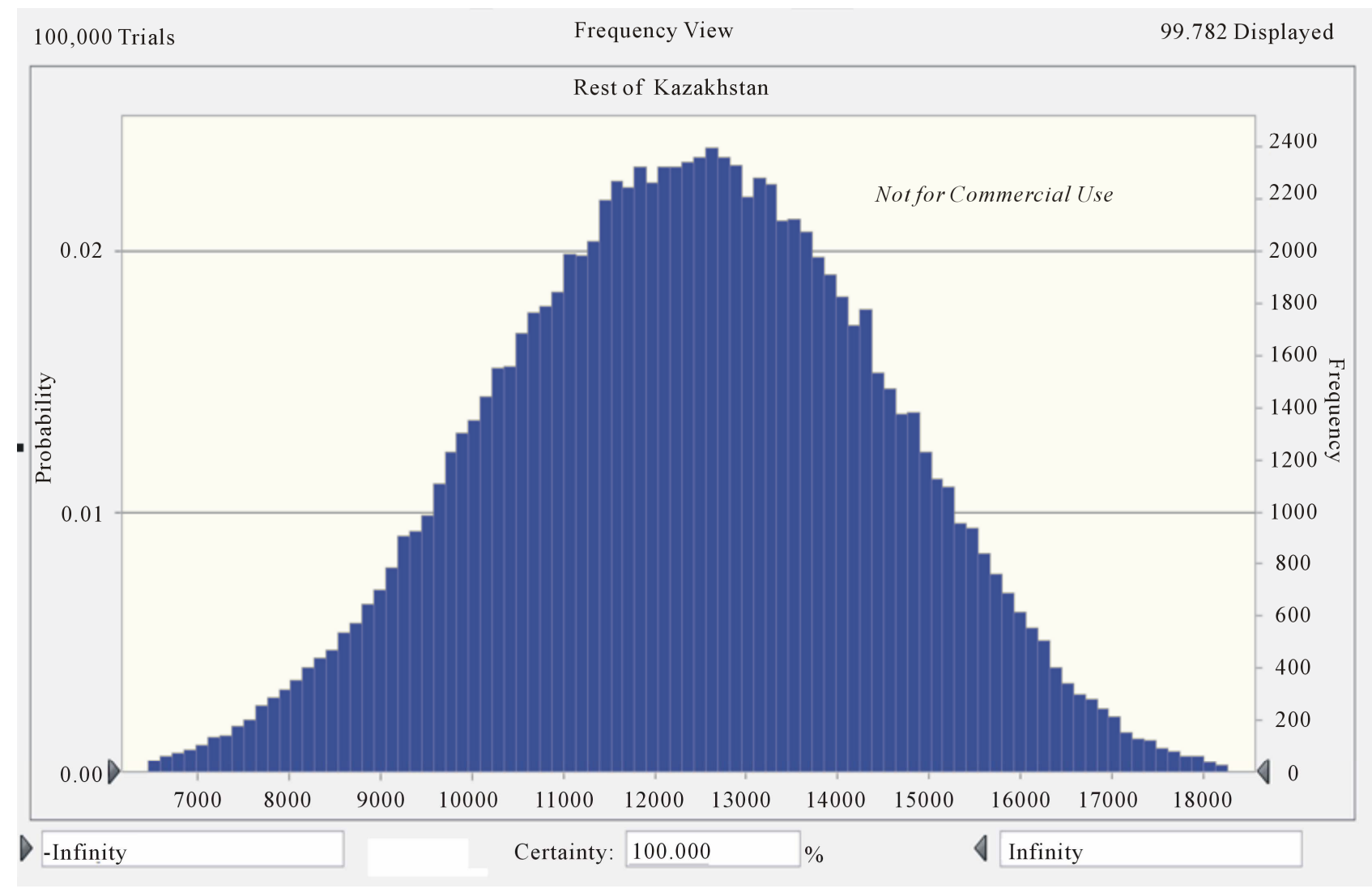

Figure 2. Mortality attributed to PM2.5 pollution for the rest of Kazakhstan.

Table 6. Comparison of air pollution attributed mortality with other mortality causes in Kazakhstan, Russia and Ukraine per 100,000 of population.

\begin{tabular}{cccc}
\hline & Kazakhstan & Russia & Ukraine \\
\hline $\begin{array}{c}\text { All internal causes of } \\
\text { death }\end{array}$ & 940 & 1228 & 1500 \\
Air pollution & $48.5-84.8$ & 59 & 55 \\
\hline
\end{tabular}

Source: authors calculations; official national statistics, [4,5].

Based on the sensitivity analyses, we can formulate priorities for the improvement of mortality risk estimates. The concentration-response coefficient that is accountable for more than $40 \%$ of the sensitivity could be tailored to the specifics of confounding factors in Kazakhstan. For example, this coefficient could be adjusted based on the actual proportion of smokers. A field study of TSP and PM would be another important step towards improving risk estimates. Also, more precise mapping of the population relative to ambient concentration will reduce uncertainty.

Nevertheless, even with all the uncertainties mentioned above, we can conclude that air pollution in Kazakhstan constitutes a significant contribution to the environmental burden of diseases. And as it was beyond the scope, this study did not look at levels of more general cardio-pul- monary diseases, or rates of lung cancer. And in addition to the uncertainties addressed in this paper, no other impacts of air pollution were addressed at all. This includes widespread compounds like ozone, but also would include other facility specific emissions such as heavy metals or VOCs. In relative terms, the impact of air pollution to premature mortality in Kazakhstan is notably higher than in Russia and the Ukraine.

The GDP of Kazakhstan is within the top 50 of the world. As its economy continues to grow, as it further integrates into the world's economy and political organizations it should also develop a science-based approach to air pollution control to improve the health of the population. In the US, control of particulates was shown to be the most cost-effective health regulation of the Federal Government [13]. And studies continue to corroborate and elaborate on the health damages from fine particulates [19]. This analysis is a start on the scientific foundation of the severe and significant air pollution effects in Kazakhstan and for the eventual control of this pollution.

\section{REFERENCES}

[1] B. Larson, S. Avaliani, A. Golub, et al., "The Economics of Air Pollution Health Risks in Russia: A Case Study of Volgograd," World Development, Vol. 27, 10, No. 1999, 


\section{pp. 1803-1819. doi:10.1016/S0305-750X(99)00086-8}

[2] G. Oniszhenko, S. Avaliani, S. Novikov, U. Rakhmanin and K. Bushtueva, "Basis for human Health Risk Assessment Resulting from Chemical Pollutants," NII ECH \& GOS, Moscow City, 2002. doi:10.1016/S0305-750X(99)00086-8

[3] S. Avaliani, D. Dudek, A. Golub and E. Strukova, "Ancillary Benefits of Climate Change Mitigation in Russia. Mitigation and Adaptation Strategies for Global Change," Mitigation and Adaptation Strategies for Global Change, 2006. doi:10.1007/s11027-006-2948-4

[4] E. Strukova, A. Golub and A. Markandya, "Air Pollution Costs in Ukraine," Fondazione Eni Enrico Mattei, Nota Di Lavoro, Milano, 2006, p. 120.

[5] A. Golub and E. Strukova, "Evaluation and Identification of Priority Air Pollutants for Environmental Management on the Basis of Risk Analysis in Russia," Journal of Toxicology and Environmental Health, Part A, Vol. 71, No. 1, 2008, pp. 86-91. doi:10.1080/15287390701558238

[6] V. Reshetin and V. Kazazyan, "Public-Health Impact of Outdoor Air Pollution in Russia," Environmental Modelling and Assessment, Vol. 9, No. 1, 2004, pp. 43-50.

[7] B. Ostro, "Outdoor Air Pollution: Assessing the Environmental Burden of Disease at National and Local Levels," World Health Organization, Geneva, WHO Environmental Burden of Disease Series, No 5, 2004.

[8] S. Avaliani and B. Revich, "Human Health Environmental Pollution Risk Assessment as a Tool for Moscow Region Municipal Environmental Policy," News Library, Moscow City, 2010, p. 311.

[9] A. J. Cohen, H. R. Anderson, B. Ostro, K. D. Pandey, M. Krzyzanowski, N. Kuenzli, K. Gutschmidt, C. A. Pope, I. Romieu, J. M. Samet and K. R. Smith, "Mortality impacts of urban air pollution," In: M. Ezzati, A. D. Lopez, A. Rodgers and C. U. J. L. Murray, Eds., Comparative Quantification of Health Risks: Global and Regional Burden of Disease Due to Selected Major Risk Factors, Vol. 2, World Health Organization, Geneva, 2004, pp. 13531433.

[10] A. Shahsavani,, K. Naddafi, N. J. Haghighifard, M. Mesdaghinia, M. Yunesian, R. Nabizadeh, M. Arahami, M. Sowlat, M. Yarahmadi, H. Saki, M. Alimohamadi, S. Nazmara, S. Motevalian and G. Goudarzi, "The Evaluation of $\mathrm{PM}_{10}, \mathrm{PM}_{2.5}$, and $\mathrm{PM}_{1}$ Concentrations during the Middle Eastern Dust (MED) Events in Ahvaz, Iran, from
April through September 2010," Journal of Arid Environments, Vol. 77, 2012, pp. 72-83. doi:10.1016/j.jaridenv.2011.09.007

[11] M. Brauer, M. Amann, R. T. Burnett, A. Cohen, F. Dentener, M. Ezzati, S. B. Henderson, M. Kryzanowski, R. V. Vartin, R. V. Dingenen, A. van Donkelaar and G. D. Thurston, "Exposure Assessment for Estimation of the Global Burden of Disease Attributable to Outdoor Air Pollution," Environmental Science \& Technology, Vol. 46, No. 2, 2012, pp. 652-660. doi:10.1021/es2025752

[12] WHO, "The World Health Report 2002—Reducing Risks, Promoting Healthy Life," 2002. http://www.who.int/whr/2002/en/

[13] C. A. Pope III, R. T. Burnett, M. J. Thun, et al., "Lung cancer, Cardiopulmonary mortality, and Long-term Exposure to Fine Particulate Air Pollution," Journal of the American Medical Association, Vol. 287, No. 9, 2002, pp. 1132-1141. doi:10.1001/jama.287.9.1132

[14] D. W. Dockery, "Health Effects of Particulate Air Pollution," Annals of Epidemiology, Vol. 19, No. 4, 2009, pp. 257-263. doi:10.1016/i.annepidem.2009.01.018

[15] D. Zmirou, J. Schwartz, M. Saez, A. Zanobetti, B. Wojtyniak, G. Touloumi, C. Spix, A. Ponce de Leon, Y. Le Moullec, L. Bacharova, J. Schouten, A. Ponka and K. Katsouyanru, "Time-Series Analysis of Air Pollution and Cause-Specific Mortality," Epidemiology, Vol. 9, No. 5, 1998, pp. 495-503. doi:10.1097/00001648-199809000-00005

[16] N. Fann, A. Lamson, S. Anenberg, K. Wesson, D. Risley and B. Hubbell, "Estimating the National Public Health Burden Associated with Exposure to Ambient $\mathrm{PM}_{2.5}$ and Ozone," Risk Analysis, Vol. 32, No. 1, 2012, pp. 81-95.

[17] WDI, "World Development Indicators," World Bank, 2012. http://data.worldbank.org/country/kazakhstan

[18] E. Strukova, J. Balbus and A. Golub, "Saving Lives, Saving Money: Regulating Particulate Matter Air Pollution in Russia," Environmental Defense Fund, 2007. http://apps.edf.org/documents/6628_SavingLivesSaving Money.pdf

[19] J. O. Anderson, J. G. Thundiyil and A. Stolbach, "Clearing the Air: A Review of the Effects of Particulate Matter Air Pollution on Human Health," Journal of Medical Toxicology, Vol. 8, No. 2, 2012, pp. 166-175. doi:10.1007/s13181-011-0203-1 